\title{
Longitudinal Changes in The Association Between Coffee Intake and Ischaemic Heart Disease From 1990 to 2018: An International Ecological Study
}

Yoshiro SHIRAI ( $\square$ y-shirai@kinjo-u.ac.jp )

Kinjo Gakuin University

\section{Tomoko IMAI}

Doshisha Women's College of Liberal Arts

\section{Ayako SEZAKI}

Nagoya University of Arts and Sciences

Keiko MIYAMOTO

Nagoya University of Arts and Sciences

Fumiya KAWASE

Asuke Hospital Aichi Prefectural Welfare Federation of Agricultural Cooperatives

Chisato ABE

Tsu City College

Masayo SANADA

Nagoya University of Arts and Sciences

\section{Ayaka INDEN}

Nagoya University of Arts and Sciences

Takumi KATO

Japanese Red Cross Aichi Medical Centre Nagoya Daini Hospital

Norie SUZUKI-SUGIHARA

Ochanomizu University

Hiroshi SHIMOKATA

Nagoya University of Arts and Sciences

\section{Research Article}

Keywords: Coffee, Ischaemic heart disease, Longitudinal study, Ecological study

Posted Date: November 8th, 2021

DOl: https://doi.org/10.21203/rs.3.rs-993390/v1

License: (a) (i) This work is licensed under a Creative Commons Attribution 4.0 International License. Read Full License 
Page $2 / 17$ 


\section{Abstract}

In previous observational studies, the association between coffee consumption and the risk of cardiovascular disease has reversed from positive to negative over time. This long-term international ecological study examined whether the association between coffee intake and the mortality and incidence rates of ischaemic heart disease (IHD) changed between 1990 and 2018. We obtained data on coffee intake per capita (cups per day) and IHD mortality and incidence per 100,000 population, and socioeconomic and lifestyle indicators for each country from various publicly available databases. We integrated and analysed data from 147 countries with populations of $\geq 1$ million. We employed a linear mixed model analysis to assess the interaction among coffee intake, IHD mortality and incidence rates by year. The random effects in the mixed model were the intercept and slope by year for each country. The mean global coffee intake increased $(p<0.001)$, while IHD mortality $(p<0.001)$ and incidence $(p=0.073)$ decreased. In all models, the interaction between coffee intake and year showed a significant inverse association for IHD mortality and incidence rates ( $<<0.001$ for all). The country-level association between coffee intake and IHD mortality and incidence rates was stronger in the negative direction between 1990 and 2018.

\section{Introduction}

Coffee is the most widely consumed beverage in the world. Its public health importance led to studies of its association with cardiovascular health. Basic and clinical research has shown that caffeine and polyphenols (especially chlorogenic acid), which are typical constituents of coffee, have a positive impact on cardiovascular health [1]. An observational study conducted in 1963 was the first to report an association between coffee consumption and a higher risk of developing coronary heart disease [2]. Since then, numerous studies have reported on the issue, but the results have been inconsistent and debatable whether coffee consumption is associated with a higher, lower, or no risk of death from cardiovascular disease (CVD), including ischaemic heart disease (IHD) [3-13].

In previous studies, the observed association between coffee consumption and the risk of heart disease has changed over time. A recent meta-analysis of observational studies reported a preventive association between coffee consumption and the risk of CVD. However, when the analysis included only articles published before 2000, there was no significant association [14]. Observational studies published in 1976, 1986, 1987 and 1990 reported a higher risk of IHD with coffee consumption [5, 7, 8, 12], studies published between 1990 and 2008 reported no association [4, 6, 9, 10, 13, 15], and studies published in 2011, 2012 and 2017 reported a preventive association $[3,11,16]$. These findings suggest that the association between coffee consumption and IHD risk might have changed between pre-1990 and recent times. The change in the results from these reports may be due to factors associated with the changing times (e.g. coffee brewing habits, diet, lifestyle, advances in medicine and drug treatment) or due to research-related factors, such as improved methodologies and publication bias. Examining whether the relationship between food intake and disease risk can change over time is an important issue in nutritional epidemiology. 
Therefore, to clarify whether the association between coffee intake and IHD mortality and incidence rates at the country-level has changed with time (1990-2018), we conducted a longitudinal ecological study using an international database.

\section{Methods}

\section{Age-standardised mortality and incidence rate of ischaemic heart disease}

We obtained the annual age-standardised IHD mortality and incidence rates per 100,000 population for each country from 1990 to 2018 from the Global Burden of Disease Study (GBD) 2019 [17]. The GBD is a comprehensive programme of global and regional burden studies conducted by the University of Washington's Institute for Health Metrics and Evaluation as an international collaboration of more than 145 countries [18]. The estimates of the GBD adhere to the Guidelines for Accurate and Transparent Health Estimates Reporting standards developed by the World Health Organisation and other organisations.

\section{Coffee intake}

We obtained coffee intake data (cups/day/population) (1 cup = $8 \mathrm{oz}$ ) for each country in 1990, 1995, 2000, 2005, 2010, 2015 and 2018 from the Global Dietary Database (GDD) [19]. The GDD is an ongoing collaborative effort to produce the most reliable estimates of worldwide dietary intake to inform research and policymaking on health and nutrition worldwide. Data from the GDD are employed to estimate individual food and nutrient intake worldwide by country, year, sex, etc. The estimates are used to determine the disease burden and evaluate and improve public health and nutrition policies, among other purposes. The GDD has identified and obtained data for 1634 eligible survey years of data from public and private sources. Of these, 1240 have been checked, standardised, and approved for inclusion in the GDD 2018 model. Information on handling cases where country-representative surveys are not available, as well as coding methods and the GDD 2018 prediction model and its validation, are described elsewhere [20].

\section{Coffee supply}

Information on coffee supplies was obtained from the food balance sheet published by the United Nations Food and Agriculture Organisation (FAO). The data are available from the FAO Statistics Division database (FAOSTAT), which provides the public with annual data on more than 245 countries and territories [21]. The data are calculated based on various statistics and sources from each country; the domestic supply of each food item is the amount of food produced and imported minus the amount of food exported. The food supply is calculated as the domestic supply minus food losses and food used for feed and seed. Currently, data are available from 1961 to 2018. Given that the methodology for estimating the data has changed since 2014, we used data from 1990 (when GBD data were made available) to 2013 (before the change in the estimating methodology) to determine the mean coffee supply ( $\mathrm{g} /$ day/capita) by country. Further details can be found elsewhere [22].

\section{Socioeconomic and lifestyle indicators}


Multiple socioeconomic and lifestyle factors are associated with the incidence of IHD and mortality. To exclude the influence of these factors, we obtained covariates that might affect IHD. For the socioeconomic indicators, we obtained data from the World Bank database from 1990 to 2013 on the gross domestic product (GDP) per capita (US $\$ 1000 /$ capita), ageing rate (percentage of the population aged 65 years and older) and total population by country [23].

We obtained lifestyle factors from the GBD covariate database from 1990 to 2019. It included energy intake (total kcal/day/population), mean age-standardised alcohol consumption ( $\mathrm{g} /$ day/population), years of education, age-standardised current smoking rate (\%), age-standardised physical activity (1000 metabolic equivalents-min/week), mean body mass index (BMI) for individuals older than 20 years $(\mathrm{kg} / \mathrm{m} 2)$, age-standardised mean systolic blood pressure (SBP) $(\mathrm{mm} \mathrm{Hg})$ and age-standardised mean lowdensity lipoprotein cholesterol level (LDL-C) (converting $\mathrm{mmol}$ to $\mathrm{mg} / \mathrm{dl}$ by dividing by 0.02586 ) [24]. We also obtained the alcohol supply (grams of ethanol/day/capita) and energy supply (kcal/day/capita) by country from FAOSTAT.

Covariates for lifestyle factors such as smoking, BMI and physical activity were taken from the countryspecific frequencies and distributions. Since this study was conducted on a country-by-country basis, the age and sex of the individuals in the analysis could not be included. Forage, however, we used the ageing rate as a covariate. The sex distribution is almost the same in all countries, and when compared across countries, there is little bias due to differences in sex distribution. To account for various regional differences, such as cultural and climatic differences, we also used the "Super Regions" as covariates, which are the seven regions of the GBD's country classification: Central Europe, Eastern Europe and Central Asia; Latin America and Caribbean; North Africa and Middle East; South Asia; Southeast Asia, East Asia and Oceania; Sub-Saharan Africa; and High-income.

\section{Statistical analysis}

The present analysis used a variety of statistical data from those years in which no variables were missing. We limited our analysis to countries with populations of 1 million or more. Countries with smaller populations often do not have their own statistical systems, year-to-year variations in statistical values can be large, and outliers can significantly impact the overall results. For our analysis, we included 147 countries for which all data were available.

We examined the distribution and change over time in IHD mortality and incidence rates, coffee intake, socioeconomic indicators and lifestyles. We tested the trend of the mean values of each variable in 1990 (the first year of the analysis), 2000 (the early middle year), 2010 (the late middle year) and 2018 (the last year) with a general linear model. We divided the countries based on the Super Regions, calculated the population-weighted mean values for coffee consumption, IHD mortality and incidence rates by region for each year, and plotted them using the locally estimated scatterplot smoothing method.

To examine the association between coffee intake and IHD mortality and incidence rates and the changes in the association by year, we conducted a linear mixed model analysis using each country's IHD mortality and incidence rates over 28 years from 1990 to 2018 as the dependent variables. We used the independent 
variables of coffee intake, year and the interaction between coffee intake and year. No covariates were added to Model 1, GDP was a covariate in Model 2 and GDP, ageing rate, years of education, smoking rate, physical activity and energy supply were covariates in Model 3. All independent variables centred on the grand mean. The random effects in the mixed model were the intercept and slope of the year for each country. We also specified a composite symmetric structure for the covariance matrix for each country and year. The fitting of the model was performed by maximising the log-likelihood.

For the sensitivity analyses, we further adjusted for alcohol consumption, BMI, SBP, LDL-C and Super Regions to test the robustness of the results. For all of the above analyses over 23 years from 1990 to 2013 , we changed the independent variable from the coffee intake data from the GDD to the coffee supply data obtained from the FAOSTAT, and the covariate was changed from the GBD's energy intake and alcohol consumption to the FAOSTAT's energy supply and alcohol supply.

We used R 4.0.5 for the analysis [25], and p-values $<0.05$ were considered statistically significant. The generalised linear mixed-effects models were fitted using the "Ime" function of the "nlme" package [26].

\section{Ethical Consideration}

This study was carried out in compliance with Declaration of Helsinki. Only publicly available data was used in this study, and no personal information was handled.

\section{Results}

Table 1 shows the means and standard deviations of the variables among the countries and the results of the trend tests. The mean global coffee intake increased between 1990 and $2018(p<0.001)$, while the mean global IHD mortality rate and incidence rate decreased from 1990 to $2018(p<0.001$ and $p=0.073$, respectively). The socioeconomic variables, GDP, ageing rate and years of education showed significant upward trends ( $p<0.001$ for all), whereas the lifestyle variable of smoking showed an inverse trend $(p<$ $0.001)$. Total energy intake, BMI and SBP trended upward ( $p<0.001$ for all). 
Table 1

Characteristics of the countries by year.

\begin{tabular}{|c|c|c|c|c|c|c|c|c|c|}
\hline & \multicolumn{2}{|l|}{1990} & \multicolumn{2}{|l|}{2000} & \multicolumn{2}{|l|}{2010} & \multicolumn{2}{|l|}{2018} & \multirow{2}{*}{$\begin{array}{l}\mathrm{p} \\
\text { trend }\end{array}$} \\
\hline & Mean & SD & Mean & SD & Mean & SD & Mean & SD & \\
\hline$n$ & 125 & & 140 & & 146 & & 144 & & \\
\hline $\begin{array}{l}\text { Coffee intake } \\
\text { (cups/d) }\end{array}$ & 0.4 & 0.5 & 0.5 & 0.5 & 0.7 & 0.6 & 0.8 & 0.6 & $<0.001$ \\
\hline $\begin{array}{l}\text { IHD incidence rate } \\
(100,000 / y)\end{array}$ & 338.7 & 182.6 & 330.6 & 189.1 & 321.0 & 194.7 & 311.2 & 187.4 & 0.073 \\
\hline $\begin{array}{l}\text { IHD mortality rate } \\
(100,000 / y)\end{array}$ & 187.6 & 92.9 & 179.1 & 108.3 & 160.9 & 107.6 & 147.5 & 99.5 & $<0.001$ \\
\hline $\begin{array}{l}\text { GDP (US } \\
\$ 1,000 / \text { capita) }\end{array}$ & 5.4 & 8.4 & 6.1 & 9.6 & 12.6 & 17.5 & 14.4 & 19.2 & $<0.001$ \\
\hline $\begin{array}{l}\text { Population (million } \\
\text { population) }\end{array}$ & 40.1 & 130.0 & 42.1 & 141.7 & 46.0 & 153.6 & 50.3 & 165.2 & 0.398 \\
\hline Ageing rate (\%) & 6.2 & 4.2 & 7.2 & 4.9 & 7.9 & 5.6 & 9.1 & 6.6 & $<0.001$ \\
\hline Years of education & 6.0 & 3.4 & 7.0 & 3.4 & 8.0 & 3.3 & 8.9 & 3.2 & $<0.001$ \\
\hline $\begin{array}{l}\text { Current smoking } \\
\text { rate (\%) }\end{array}$ & 22.2 & 8.9 & 20.7 & 8.8 & 19.4 & 8.3 & 18.5 & 7.8 & $<0.001$ \\
\hline $\begin{array}{l}\text { Alcohol supply } \\
\text { (g/d/capita) }\end{array}$ & 10.6 & 7.9 & 10.5 & 7.6 & 10.2 & 7.6 & 10.3 & 7.6 & 0.537 \\
\hline $\begin{array}{l}\text { Physical activity } \\
(1,000 \\
\text { METs·min/wk) }\end{array}$ & 5.4 & 1.8 & 5.5 & 1.8 & 5.4 & 1.8 & 5.4 & 1.8 & 0.988 \\
\hline $\begin{array}{l}\text { Total energy intake } \\
(1,000 \\
\text { kcal/d/capita })\end{array}$ & 2.5 & 0.4 & 2.5 & 0.4 & 2.6 & 0.4 & 2.7 & 0.4 & $<0.001$ \\
\hline BMI $\left(\mathrm{kg} / \mathrm{m}^{2}\right)$ & 24.0 & 1.8 & 24.5 & 2.0 & 25.1 & 2.1 & 25.6 & 2.2 & $<0.001$ \\
\hline SBP (mm Hg) & 127.7 & 4.5 & 128.4 & 4.4 & 128.9 & 4.3 & 129.4 & 4.2 & $<0.001$ \\
\hline LDL-C (mg/dl) & 110.2 & 21.0 & 111.1 & 19.2 & 111.7 & 17.3 & 112.7 & 16.9 & 0.261 \\
\hline
\end{tabular}

Figure 1 shows the changes in coffee intake and IHD mortality and the incidence rates from 1990 to 2018, globally and for the GBD Super Regions. Although coffee consumption increased slowly overall, it increased significantly in Central Europe, Eastern Europe and Central Asia Super Region between 1995 and 
2005. Despite large regional differences in IHD mortality and incidence, the overall trend was flat or decreasing.

Tables 2 and 3 show the fixed effects for coffee intake, year, the interaction between coffee intake and year, and covariates on the IHD mortality rate and incidence rates, respectively, in the three linear mixed-effects models. In all models, the interaction between coffee intake and year showed a significant inverse association ( $p<0.001$ for all in Table 2; $p<0.001$ for all in Table 3). The significant interaction between coffee intake and year in Model 3 was also shown by further adjusting for alcohol consumption, BMI, SBP, LDL-C, Super Region and all of these in sensitivity analyses. In the order of the adjustment factors listed above, the fixed effects for the IHD mortality rate were $-1.298,-1.270,-1.169,-1.280,-1.398$ and -1.220 , and those for the IHD incidence rate were $-0.969,-0.928,-0.829,-0.958,-0.955$ and $-0.827(p<0.001$ for all). In the analysis where the independent variable was coffee supply (data from FAOSTAT), the association was similar to coffee intake (Supplementary Tables S1 and S2). 
Table 2

Fixed effects of coffee supply, year, coffee supply-year interaction and covariates on IHD mortality in the 3 linear mixed-effects models.

\begin{tabular}{|c|c|c|c|c|c|c|c|c|c|}
\hline & Model 1 & & & Model 2 & & & Model 3 & & \\
\hline & $\beta(\mathrm{SE})$ & & & $\beta$ (SE) & & & $\beta(\mathrm{SE})$ & & \\
\hline (Intercept) & 172.972 & (8.548) & $\star \star \star ~$ & 173.010 & (8.444) & $\star \star \star$ & 173.762 & (9.833) & *** \\
\hline Coffee intake & -9.286 & $(2.376)$ & $\star \star \star$ & -8.268 & (2.381) & $\star \star \star$ & -9.909 & (2.209) & *** \\
\hline Year & -1.769 & $(0.243)$ & $\star \star \star ~$ & -1.551 & $(0.241)$ & $\star \star \star$ & -2.141 & $(0.408)$ & $* * *$ \\
\hline Coffee*Year & -1.441 & $(0.181)$ & 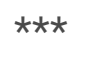 & -1.386 & $(0.181)$ & $\star \star \star$ & -1.194 & $(0.170)$ & $\star * *$ \\
\hline GDP & & & & -0.685 & $(0.171)$ & $\star \star \star$ & -0.206 & $(0.166)$ & \\
\hline Energy intake & & & & & & & -109.379 & (8.471) & $\star \star \star \star$ \\
\hline $\begin{array}{l}\text { Current } \\
\text { smoking rate }\end{array}$ & & & & & & & 0.616 & $(0.428)$ & \\
\hline $\begin{array}{l}\text { Physical } \\
\text { activity }\end{array}$ & & & & & & & -6.365 & (5.291) & \\
\hline Ageing rate & & & & & & & 7.558 & $(0.866)$ & *** \\
\hline $\begin{array}{l}\text { Years of } \\
\text { education }\end{array}$ & & & & & & & 6.029 & $(2.690)$ & * \\
\hline AIC & 18067.8 & & & 18056.1 & & & 17805.8 & & \\
\hline $\mathrm{BIC}$ & 18118.1 & & & 18111.9 & & & 17889.5 & & \\
\hline \multicolumn{10}{|c|}{$\begin{array}{l}\text { GDP, gross domestic product; BMI, body mass index: AIC, Akaike's information criterion; BIC, Bayesian } \\
\text { information criterion; SE, standard error }\end{array}$} \\
\hline \multicolumn{10}{|c|}{ *** $p<0.001$, ** $p<0.01, * p<0.05$} \\
\hline
\end{tabular}


Table 3

Fixed effects of coffee supply, year, coffee supply-year interaction and covariates on the IHD incidence in the 3 linear mixed-effects models.

\begin{tabular}{|c|c|c|c|c|c|c|c|c|c|}
\hline & Model 1 & & & Model 2 & & & Model 3 & & \\
\hline & $\beta$ (SE) & & & $\beta$ (SE) & & & $\beta$ (SE) & & \\
\hline (Intercept) & 330.849 & (15.769) & $\star \star \star *$ & 330.897 & (15.748) & $\star \star \star *$ & 331.569 & (16.855) & $\star \star \star *$ \\
\hline $\begin{array}{l}\text { Coffee } \\
\text { intake }\end{array}$ & -5.969 & (2.066) & $\star *$ & -5.265 & $(2.070)$ & * & -6.266 & (1.917) & ** \\
\hline Year & -1.151 & $(0.223)$ & $\star \star \star \star$ & -0.976 & $(0.221)$ & $\star \star \star *$ & -1.276 & $(0.451)$ & ** \\
\hline Coffee*Year & -1.112 & $(0.157)$ & $\star \star \star \star$ & -1.076 & $(0.157)$ & $\star \star \star \star$ & -0.869 & $(0.147)$ & $\star \star \star *$ \\
\hline GDP & & & & -0.550 & $(0.153)$ & $\star * *$ & -0.089 & $(0.145)$ & \\
\hline $\begin{array}{l}\text { Energy } \\
\text { intake }\end{array}$ & & & & & & & -104.410 & (7.687) & $\star * *$ \\
\hline $\begin{array}{l}\text { Current } \\
\text { smoking } \\
\text { rate }\end{array}$ & & & & & & & 0.794 & $(0.382)$ & * \\
\hline $\begin{array}{l}\text { Physical } \\
\text { activity }\end{array}$ & & & & & & & -19.683 & (7.766) & * \\
\hline Ageing rate & & & & & & & 6.444 & $(0.783)$ & $\star \star \star *$ \\
\hline $\begin{array}{l}\text { Years of } \\
\text { education }\end{array}$ & & & & & & & 3.498 & (3.335) & \\
\hline AIC & 17720.6 & & & 17712.0 & & & 17448.6 & & \\
\hline $\mathrm{BIC}$ & 17770.8 & & & 17767.8 & & & 17532.3 & & \\
\hline \multicolumn{10}{|c|}{$\begin{array}{l}\text { GDP, gross domestic product; BMI, body mass index; AIC, Akaike's information criterion; BIC, Bayesian } \\
\text { information criterion; SE, standard error }\end{array}$} \\
\hline \multicolumn{10}{|c|}{$\star \star * p<0.001, * * p<0.01, * p<0.05$} \\
\hline
\end{tabular}

We examined the associations between coffee intake and IHD mortality and incidence rate by year using the mixed-effects model, controlling for covariates in Model 3. The estimated association between coffee intake and IHD mortality and incidence rate in 1990, 1995, 2000, 2005, 2010, 2015 and 2018 is shown in Figure 2. The slope of coffee intake on the mortality and incidence of IHD reversed from positive to negative and increased over the years. The IHD mortality rate slope was positive in $1990(\beta=9.55, p=$ $0.059)$ and $1991(\beta=8.25, p=0.091)$, then unrelated until 2001 and then negative from $2002(\beta=-6.13, p$ $=0.078)$ to $2018(\beta=-27.04, p<0.001)$. The IHD incidence rate slope was positive in $1990(\beta=8.08, p=$ $0.066)$ and $1991(\beta=7.10, p=0.094)$, then unrelated until 2003 and negative from $2004(\beta=-5.69, p=$ $0.054)$ to $2018(\beta=-19.46, p<0.001)$. 


\section{Discussion}

This study used multiple international databases to show ecologically that the country-level association between coffee intake and IHD mortality and incidence rates changed from a marginally positive association in 1990 to an inverse association in 2018. The results also show the association changed in the opposite direction due to social and environmental changes. The results suggest that the inconsistent association between high IHD risk and coffee consumption reported in observational studies before 1990 and the low IHD risk after 2011 is unlikely to be research-related factors.

According to a meta-analysis of the association between coffee consumption and CVD risk, possible explanations for the lack of consistency between older and more recent observational studies include differing risks depending on how the coffee is brewed, inadequate adjustments for smoking in older studies and recall bias in case-control studies [14]. A cohort study of approximately 500,000 individuals followed for a mean of 20 years found that CVD mortality was higher in those who consumed unfiltered coffee than those who drank paper-filtered coffee. The association between unfiltered coffee consumption and higher IHD mortality was partially mediated by total cholesterol [27]. In the 1980s and 1990s, there was growing interest in the different health effects of unfiltered and paper-filtered coffee, with several studies showing differences. In the 1980s, studies showed coffee consumption increased serum cholesterol [2830]. In 1991, two clinical studies reported that the factors causing coffee consumption to raise cholesterol levels were eliminated using paper filters [31, 32]. In 1994, the cause for the increase in total serum cholesterol levels due to coffee consumption was identified as the natural components of coffee, such as cafestol and kahweol [33]. Preparation techniques for various coffee brews showed that these components in filtered coffee and instant coffee were extremely low compared with unfiltered coffee [34]. The results of these studies might have encouraged the use of paper filters for coffee brewing. Today, paper filter brewing is common in many parts of the world, especially in high-income countries. The number of studies reporting differences in coffee brewing methods in the general population is very limited. To our knowledge, only three studies were published in the 1980s [27, 35, 36], covering just Norway and Finland. These three studies had 18,012 (20-59 years), 508,747 (20-79 years) and 5704 (25-64 years) participants, and $20 \%, 68 \%$ and $24 \%$ consumed unfiltered coffee, respectively, while $59 \%, 21.5 \%$ and $69 \%$ consumed paper-filtered coffee. A significant number of individuals who drank boiled coffee might have shifted to filtered coffee in recent years, which might be one of the reasons for the change in the association between coffee consumption and IHD risk.

There has been a strong relationship between smoking cigarettes and coffee consumption [37]. In the present data, smoking rates were positively associated with IHD mortality and incidence longitudinally. Although the mean smoking rate in each country decreased by $3.7 \%$ between 1990 and 2018, the mean coffee intake in each country doubled. This change in the opposite direction for coffee intake and smoking could be one of the reasons for the change in the association between coffee intake and IHD risk.

As for changes in the social context, the evolution of information technology, which has brought about rapid changes in society since 1995, might have also influenced the association between coffee consumption and IHD risk. The Internet has made it easier for people to access various information, 
making medical and health information more accessible and likely enhancing public health awareness. If individuals have healthier diets and other lifestyle habits, fewer people will develop IHD and die from it. For instance, some people drink coffee with added sugar and milk (including saturated fatty acids). When sugar and saturated fatty acids in coffee are reduced (replaced with starch and polyunsaturated fatty acids), coffee consumption is reportedly more favourable for cardiovascular health $[38,39]$. With medical and pharmaceutical advances, the number of deaths from IHD are expected to decrease, regardless of coffee consumption. In our study, the decline was more pronounced in the IHD mortality rate (-40.1) than in the incidence rate (-27.5), and the interaction between coffee intake and the year was negatively significant, indicating that the higher the coffee intake, the greater the reduction in IHD mortality and the incidence rate between 1990 and 2018. These changes in the social context might have affected the change in the association between coffee consumption and IHD risk.

The limitations of this study include the fact that it is a country-level ecological study, which cannot take into account individual age, sex, race, coffee brewing methods and additives, dietary habits and the effects of selection bias unmeasured confounders remain. However, important confounding factors, such as smoking and physical activity, were taken into account. Although coffee brewing methods, use of additives, and the level of healthcare provision can vary by region, the results did not change when we included 7 GBD Super Regions in the model. The results also remained in the models that included alcohol consumption, BMI, blood pressure, LDL-C, or all of these factors associated with IHD mortality and incidence. Furthermore, the FAOSTAT data (1990-2013), which estimated the food supply, and GDD, which estimated the food intake, were analysed for 137 countries. The associations between coffee supply and IHD mortality and incidence rates were analysed similarly to the results of the GDD analysis. A further limitation is that we were unable to evaluate the relationship before 1990. Although reports indicating that coffee increased the risk of heart disease were mainly from the 1980s, data from this period were not available for the present study.

One of the strengths of this long-term ecological study is that the data employed in the analysis were estimated at the national level from multiple databases by researchers unrelated to this research project. The data objectively showed the association between coffee intake and IHD mortality and incidence rates. Therefore, this study cannot explain the causal relationship between coffee consumption and IHD mortality and incidence due to the study design. Still, it did reveal that the association has changed over time. The results suggest that the period-specific associations, from high cardiovascular risk with coffee consumption around 1990 to no association around 2000 and low cardiovascular risk with coffee consumption after that, might have represented actual real-world associations. We propose that the association between dietary habits and disease risk in a given era (especially the results of older studies) can change long due to changes in various factors associated with the changing times.

\section{Declarations}

\section{Data availability}

All data used in this study are available from the corresponding author upon reasonable request. 


\section{Acknowledgements}

The authors would like to thank Enago (www.enago.jp) for the English language review.

\section{Author contributions}

All authors contributed to the study's conception and design. The data analysis was performed by Y.S. and H.S. The first draft of the manuscript was written by Y.S., and all authors commented on the previous versions of the manuscript. All authors have reviewed and approved the final manuscript as submitted.

\section{Funding}

Source(s) of support: English proofreading and APC were funded by Kinjo Gakuin University, to which the first author belongs.

\section{Competing interests}

The authors declare no competing interests.

\section{References}

1. Godos, J. et al. Coffee components and cardiovascular risk: beneficial and detrimental effects. Int. J. Food Sci. Nutr. 65, 925-936 (2014). 10.3109/09637486.2014.940287, Pubmed:25046596

2. Paul, O. et al. A longitudinal study of coronary heart disease. Circulation 28, 20-31 (1963). 10.1161/01.cir.28.1.20, Pubmed:13941964

3. Freedman, N. D., Park, Y., Abnet, C. C., Hollenbeck, A. R. \& Sinha, R. Association of coffee drinking with total and cause-specific mortality. N. Engl. J. Med. 366, 1891-1904 (2012). 10.1056/NEJMoa1112010, Pubmed:22591295

4. Grobbee, D. E. et al. Coffee, caffeine, and cardiovascular disease in men. N. Engl. J. Med. 323, 10261032 (1990). 10.1056/NEJM199010113231504, Pubmed:2215561

5. Hennekens, C. H., Drolette, M. E., Jesse, M. J., Davies, J. E. \& Hutchison, G. B. Coffee drinking and death due to coronary heart disease. N. Engl. J. Med. 294, 633-636 (1976). 10.1056/NEJM197603182941203, Pubmed:1246256

6. Kleemola, P., Jousilahti, P., Pietinen, P., Vartiainen, E. \& Tuomilehto, J. Coffee consumption and the risk of coronary heart disease and death. Arch. Intern. Med. 160, 3393-3400 (2000). 10.1001/archinte.160.22.3393, Pubmed:11112231

7. LaCroix, A. Z., Mead, L. A., Liang, K. Y., Thomas, C. B. \& Pearson, T. A. Coffee consumption and the incidence of coronary heart disease. N. Engl. J. Med. 315, 977-982 (1986). 10.1056/NEJM198610163151601, Pubmed:3762618

8. LeGrady, D. et al. Coffee consumption and mortality in the Chicago Western Electric Company Study. Am. J. Epidemiol. 126, 803-812 (1987). 10.1093/oxfordjournals.aje.a114717, Pubmed:3661528 
9. Lopez-Garcia, E., van Dam, R. M., Li, T. Y., Rodriguez-Artalejo, F. \& Hu, F. B. The relationship of coffee consumption with mortality. Ann. Intern. Med. 148, 904-914 (2008). 10.7326/0003-4819-148-12200806170-00003, Pubmed:18559841

10. Lopez-Garcia, E. et al. Coffee consumption and coronary heart disease in men and women: a prospective cohort study. Circulation 113, 2045-2053 (2006).

10.1161/CIRCULATIONAHA.105.598664, Pubmed:16636169

11. Mineharu, Y. et al. Coffee, green tea, black tea and oolong tea consumption and risk of mortality from cardiovascular disease in Japanese men and women. J. Epidemiol. Commun. Health 65, 230-240 (2011). 10.1136/jech.2009.097311, Pubmed:19996359

12. Tverdal, A. et al. Coffee consumption and death from coronary heart disease in middle aged Norwegian men and women. BMJ 300, 566-569 (1990). 10.1136/bmj.300.6724.566, Pubmed:2108750

13. Willett, W. C. et al. Coffee consumption and coronary heart disease in women. A ten-year follow-up. JAMA 275, 458-462 (1996). 10.1001/jama.1996.03530300042038, Pubmed:8627967

14. Ding, M., Bhupathiraju, S. N., Satija, A., van Dam, R. M. \& Hu, F. B. Long-term coffee consumption and risk of cardiovascular disease: a systematic review and a dose-response meta-analysis of prospective cohort studies. Circulation 129, 643-659 (2014). 10.1161/CIRCULATIONAHA.113.005925, Pubmed:24201300

15. Myers, M. G. \& Basinski, A. Coffee and coronary heart disease. Arch. Intern. Med. 152, 1767-1772 (1992), Pubmed:1387780

16. Park, S. Y. et al. Association of coffee consumption with total and cause-specific mortality among nonwhite populations. Ann. Intern. Med. 167, 228-235 (2017). 10.7326/M16-2472, Pubmed:28693036

17. GBD 2019 Diseases and Injuries Collaborators. Global burden of 369 diseases and injuries in 204 countries and territories, 1990-2019: a systematic analysis for the Global Burden of Disease Study 2019. Lancet 396, 1204-1222 (2020). 10.1016/S0140-6736(20)30925-9, Pubmed:33069326

18. Institute for Health Metrics and Evaluation (Institute for Health Metrics and Evaluation, July 14 2021), Available from: http://www.healthdata.org/

19. Global dietary database. Global Dietary Database 2018 Country-Level Estimates, Available from: https://www.globaldietarydatabase.org/data-download, June 282021

20. Global dietary database. Methods (September 02 2021)

21. FAO \& FAOSTAT, Available from: http://www.fao.org/faostat/en/\#home, July 142021

22. FAO. Food and Agriculture Organization of the United Nations. Food balance sheets: A handbook (Rome, July 18 2021), Available from: http://www.fao.org/3/x9892e/x9892e00.htm

23. The World Bank. World Bank open data | data, Available from: https://data.worldbank.org/, July 14 2021

24. Global Burden of Disease Collaborative Network. Global Burden of Disease Study 2019 (GBD 2019) Covariates 1980-2019. 10.6069/CFCY-WA51, July 142021 
25. R Core Team \& R Core Team. R: A Language and Environment for Statistical Computing, Available from: https://www.R-project.org/. 2021, 2021

26. Jose Pinheiro, D. B., DebRoy, S. \& Sarkar, D. Linear and Nonlinear Mixed-Effects Models $\{R$ package version 3.1-152\}. Compr. R Arch. Network (CRAN) (2021)

27. Tverdal, A., Selmer, R., Cohen, J. M. \& Thelle, D. S. Coffee consumption and mortality from cardiovascular diseases and total mortality: does the brewing method matter? Eur. J. Prev. Cardiol. 27, 1986-1993 (2020). 10.1177/2047487320914443, Pubmed:32320635

28. Arnesen, E., Førde, O. H. \& Thelle, D. S. Coffee and serum cholesterol. Br. Med. J. (Clin. Res. Ed.) 288, 1960 (1984). 10.1136/bmj.288.6435.1960, Pubmed:6428620

29. Førde, O. H., Knutsen, S. F., Arnesen, E. \& Thelle, D. S. The Tromso heart study: coffee consumption and serum lipid concentrations in men with hypercholesterolaemia: an randomised intervention study. $\mathrm{Br}$. Med. J. (Clin. Res. Ed.) 290, 893-895 (1985). 10.1136/bmj.290.6472.893, Pubmed:3919832

30. Thelle, D. S., Arnesen, E. \& Førde, O. H. The Tromso heart study. Does coffee raise serum cholesterol? N. Engl. J. Med. 308, 1454-1457 (1983). 10.1056/NEJM198306163082405, Pubmed:6855815

31. Ahola, I., Jauhiainen, M. \& Aro, A. The hypercholesterolaemic factor in boiled coffee is retained by a paper filter. J. Intern. Med. 230, 293-297 (1991). 10.1111/j.1365-2796.1991.tb00447.x, Pubmed:1919421

32. van Dusseldorp, M., Katan, M. B., van Vliet, T., Demacker, P. N. \& Stalenhoef, A. F. Cholesterol-raising factor from boiled coffee does not pass a paper filter. Arterioscler. Thromb. 11, 586-593 (1991). 10.1161/01.atv.11.3.586, Pubmed:2029499

33. Weusten-Van der Wouw, M. P., et al. Identity of the cholesterol-raising factor from boiled coffee and its effects on liver function enzymes. J. Lipid Res. 35, 721-733 (1994). 10.1016/S0022-2275(20)411691, Pubmed:7911820

34. Urgert, R. \& Katan, M. B. The cholesterol-raising factor from coffee beans. J. R. Soc. Med. 89, 618-623 (1996). 10.1177/014107689608901107, Pubmed:9135590

35. Bønaa, K., Arnesen, E., Thelle, D. S. \& Førde, O. H. Coffee and cholesterol: is it all in the brewing? The Tromso Study. BMJ 297, 1103-1104 (1988). 10.1136/bmj.297.6656.1103, Pubmed:3143443

36. Pietinen, P., Aro, A., Tuomilehto, J., Uusitalo, U. \& Korhonen, H. Consumption of boiled coffee is correlated with serum cholesterol in Finland. Int. J. Epidemiol. 19, 586-590 (1990). 10.1093/ije/19.3.586, Pubmed:2262252

37. Grosso, G. et al. Coffee consumption and risk of all-cause, cardiovascular, and cancer mortality in smokers and non-smokers: a dose-response meta-analysis. Eur. J. Epidemiol. 31, 1191-1205 (2016). 10.1007/s10654-016-0202-2, Pubmed:27699514

38. Schwingshackl, L., Neuenschwander, M., Hoffmann, G., Buyken, A. E. \& Schlesinger, S. Dietary sugars and cardiometabolic risk factors: a network meta-analysis on isocaloric substitution interventions. Am. J. Clin. Nutr. 111, 187-196 (2020). 10.1093/ajcn/nqz273, Pubmed:31711109

39. Imamura, F. et al. Effects of saturated fat, polyunsaturated fat, monounsaturated fat, and carbohydrate on glucose-insulin homeostasis: a systematic review and meta-analysis of randomised 
controlled feeding trials. PLOS Med. 13, e1002087 (2016). 10.1371/journal.pmed.1002087, Pubmed:27434027

\section{Figures}
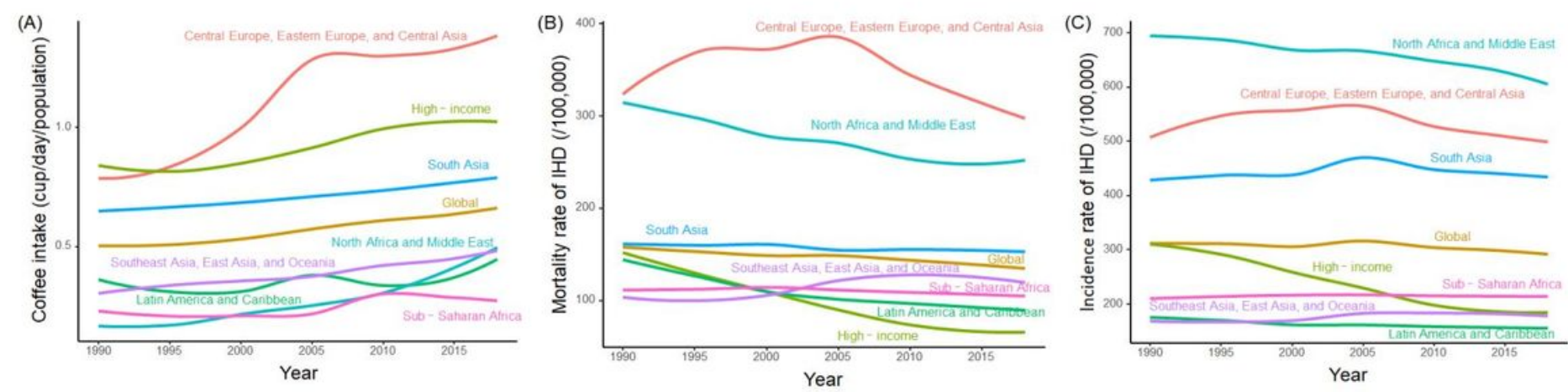

Figure 1

Changes in coffee intake (A) and mortality (B) and incidence (C) rates of ischaemic heart disease (IHD) from 1990 to 2018 globally and for GBD Super Regions.
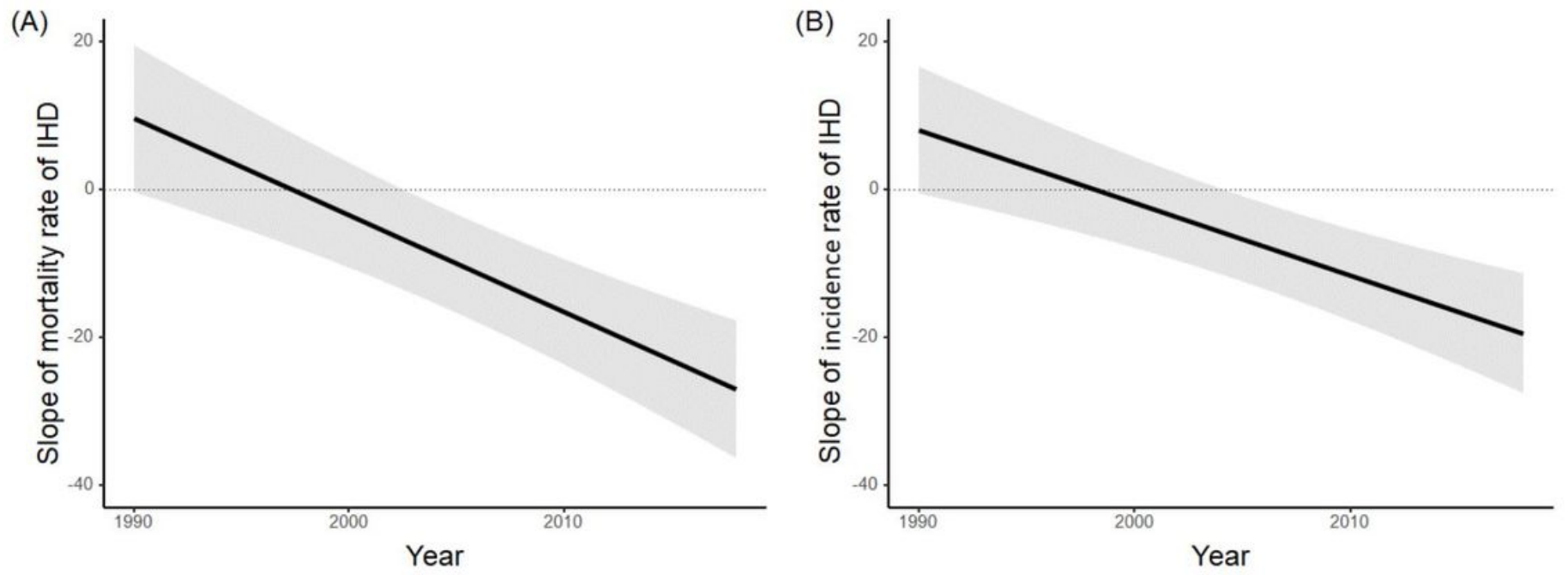

\section{Figure 2}

Estimated change in slope and $95 \%$ confidence interval of slope of the coffee intake to mortality (A) and incidence (B) rates of ischaemic heart disease (IHD) from 1990 to 2018 by mixed-effects model controlling for covariates. 


\section{Supplementary Files}

This is a list of supplementary files associated with this preprint. Click to download.

- SupplementaryTable1.pdf

- SupplementaryTable2.pdf 